\title{
Competitive market forces and trends in US hospital spending, 2001-2009
}

\author{
Vivian Y. Wu ${ }^{1^{*}}$, Yu-Chu Shen ${ }^{2,3}$, Glenn Melnick ${ }^{1}$ \\ ${ }^{1}$ University of Southern California, Los Angeles, USA; *Corresponding Author: vivianwu@usc.edu \\ ${ }^{2}$ Naval Postgraduate School, Monterey, USA \\ ${ }^{3}$ The National Bureau of Economic Research (NBER), Cambridge, USA
}

Received 10 May 2013; revised 11 June 2013; accepted 1 July 2013

Copyright (c) 2013 Vivian Y. Wu et al. This is an open access article distributed under the Creative Commons Attribution License, which permits unrestricted use, distribution, and reproduction in any medium, provided the original work is properly cited.

\begin{abstract}
Objectives: To investigate components of the rapidly increasing trend in hospital spending in the 2000's and their relationship to market structure. Study Design: Aggregate time series and multivariate analysis are conducted to test whether hospital spending growth is driven by price or quantity and how recent hospital spending growth is related to health plan and hospital market structure. Method: Hospitals are grouped into strong and weak competitive markets based on the relative concentration of hospital and health plan markets as well as managed care penetration. Results: Inflation adjusted hospital spending grew much faster than gross domestic product (GDP) throughout the 2000s. Regression results show that rapid growth was observed across all hospital markets-even in those markets where price competitive market forces are the strongest and that rising hospital prices, and not utilization explain most of the increases in hospital spending. Conclusions: Hospital spending exceeded the consumer price index (CPI) by a substantial margin in the 2000's due in part to weakening competitive market forces, which had a dampening effect on spending and especially prices. Unless competition is restored, the cost of health care for consumers, employers and public payers can be expected to increase.
\end{abstract}

Keywords: Hospital Spending; Prices; Utilization; Competitive Markets

\section{INTRODUCTION}

Recent health reform legislation includes mandates and government subsidies to extend health insurance coverage but relies on existing regulatory and marketbased approaches to control future health care spending. While competitive market forces in health care have been widely studied [1-3], empirical research covering the evolving markets in the 2000s is limited and conflicting [4-7]. For example, with consumers' switching from HMOs to less restrictive PPO plans and HMOs easing restrictions on utilization of health care services, initial reports cited an expected increase in utilization as the major driving factor behind increased health spending [8]. In contrast, recent trade journals and reports have used aggregated data to highlight the role of high prices as potential driver of increased spending in 2008-2011 in selected markets [9-15].

In this paper, we use data from all acute care hospitals in the US for the period 2001 through 2009 to document hospital spending patterns under existing and evolving market conditions as a guide to what we might expect in the future as health reform is implemented over time, particularly in light of the emerging trend of physicianhospital consolidation into integrated systems or accountable care organizations. We then use data for 2001 through 2007 to conduct multivariate regression analysis to decompose per capita hospital spending growth into quantity and price trends and assess how these two components have grown over time as a function of three inter-related hospital market structure dimensions: managed care (MC) penetration, MC plan concentration, and hospital market competition.

\section{METHODS}

The study design combines analysis of aggregate timeseries data 2001-2009 along with a multivariate regression analysis of changes between 2001 and 2007 in total per capita hospital net patient revenue across Metropolitan Statistical Areas (MSA), decomposed into price and 
quantity components. Key dimensions of the competitive structure of hospital operating environments are measured by interacting MC penetration, MC plan and hospital concentration as described below. HMO and PPO enrollment are combined within an MSA to calculate MC penetration and MC concentration measures.

\subsection{Dependent Variables}

We analyze 3 outcome variables: 1) total net patient revenue per capita; 2) total adjusted hospital days per capita; and 3) net patient revenue per adjusted day. Total hospital net revenue is a product of revenue (price) per unit of service times the quantity of services. Hospital quantity is measured by adjusted patient days as calculated by American Hospital Association (AHA) to capture total hospital volume including both inpatient and outpatient utilization. Price is measured by dividing total net patient revenue by total adjusted patient days. As MSA is the unit of analysis, individual hospital net patient revenue is first summed to the MSA level (using hospital staffed beds as weights) and then divided by MSA population to obtain a per capita value. Nominal total net patient revenue, calculated as total revenues minus discounts and contractual allowances, is deflated to real 2001 dollars using the CPI. Center of Medicare and Medicaid Services local wage index is used to adjust net patient revenue for geographic differences in input costs ${ }^{1}$.

\subsection{Independent Variables}

Competitive Market Categories. MSAs are divided into one of the 5 categories: strongest, strong, average, weak, and weakest markets based on the hospital bargaining and selective contracting literature. A large concentrated health plan (buyer) is better able to extract volume discount [16]. At the same time, the competition between hospitals (sellers) enhances a plan's ability to credibly threaten to exclude a provider from its preferred network (HMO or PPO) [17,18]. Research has also shown that managed care penetration is an important measure of health plans' ability to control hospital utilization and spending $[19,20]$. Therefore, our approach combines the three dimensions of the competitive market structure in the health insurance and hospital markets.

The "strongest" markets are where we expect health plans have the strongest bargaining power in the insurerhospital negotiations, measured as high MC penetration and high MC concentration, while facing limited hospital market power, measured as low hospital concentration.

${ }^{1}$ We scale up the values from hospitals that are observed in cost reports to the total possible universe of number of hospitals in a MSA, where the "possible number" of universe of hospitals" is the total number of hospitals that reporting to AHA each year.
We hypothesize that the effect of concentrated health plan market power will be bigger in high MC penetration than in low MC penetration areas. Therefore, we define the "strong" markets so that the difference between the "strongest" and "strong" markets represents the effect of concentrated health plan in high MC penetration areas. The "strong" markets are thus MSAs with high MC penetration, low MC concentration and low hospital concentration. Conversely, the "weakest" markets have narrow degree of health plan market power (low MC penetration and concentration) and strong hospital market power (high hospital concentration). A "weak" market is similar to that of the "weakest" except that MC concentration is high, and thus difference between the "weak" and "weakest" markets is the effect of concentrated health plan in low MC penetration areas. All other markets are grouped into the "average" markets category. The threshold for "high" and "low" markets in each measure is 50 percentile (results are not sensitive to marginal changes in the threshold) based on the average of 2001-2004/7 data to reflect the average market condition during the study period. Market concentration is measured by a Herfindahl-Hirschman Index (HHI) in a MSA.

\subsection{Control Variables}

The first-difference model controls for time invariant MSA characteristics that are correlated with hospital net patient revenue and utilization. Additionally, we control for other characteristics that may change over time, including: changes in patient severity as measured by Medicare case-mix index, per capita income, unemployment rate, and percent population that are elderly in each MSA in each year. Further, as our focus is the relationship between market forces and hospital spending, we control for the portion of hospital spending that are not influenced by market forces, i.e. the (change in) percent of total hospital revenues paid by Medicaid and Medicare within each state (payer data are not available at the MSA level).

\section{DATA SOURCES}

Hospital characteristics, utilization and net patient revenue come from American Hospital Association Annual Surveys and Medicare hospital cost reports. Managed care penetration and MC concentration measures are compiled from MSA level HMO and PPO enrollment data from Inter-study (2001 and 2004) and are supplemented by the Area Resource File and the PPS Impact file (for MSA characteristics such as the area wage index, per capita income, unemployment rate, and population structure). Hospital system measures follow Madison and Chakravarty [21,22]. We report overall trend in hospital spending and utilization between 2001 and 2009 (the most recent data available) for all general acute hospitals 
that operate continuously in MSAs in that period. For the regression analysis, we limit to 2001-2007 just prior to the recent recession because spending and utilization patterns might be different under economic contraction and our managed care data is available only up to 2004 . Outliers were removed based on the top and bottom $1 \%$ of three key variables-net patient revenue, adjusted days, and price (average revenue per adjusted day) - the final regression sample covers 2085 hospitals in 282 MSAs in both years (representing 95\% of all urban hospital spending in the US).

\section{RESULTS}

Figure 1 shows that per capita hospital spending (nominal) grew well above the CPI over the 2001-2009 period-64\% vs. 21\%. On an annual basis, hospital spending increased by an average of $6 \%$ per year while the CPI grew 2\% annually-a growth difference of 4 percentage points annually. With the reported weakening of managed care we expected a surge in hospital utilization, which would explain much of the increase in per capita hospital spending. Figure 2 presents trend data for total net patient revenue per capita and utilization (adjusted patient days) per capita. Surprisingly, utilization grew very little during the period-a total of only 9 percent, compared to the strong $42 \%$ growth in real net patient revenue, suggesting that much of the growth in total hospital spending is related to higher revenue per adjusted day. In fact, the gap between the growth in net patient revenue and adjusted day-representing revenue per day-has been increasing throughout the whole 2001-2009 period, even during recession 2008-2009.

Table 1 presents the results of the multivariate analysis designed to explore whether per capita hospital spending patterns grew differently for hospitals operating in markets with different degrees of competitive pressure. The rows in Table 1 present regression-adjusted cumulative growth in per capita total net patient revenue (real), total adjusted days and average revenue per adjusted day (real), respectively.

By looking across the columns one can observe the differential relationship between market competitive market pressure and growth rates. Between 2001 and 2007, cumulative per capita spending was slowest in the strongest markets (26\%) and greatest in the weakest markets (37\%). The quantity and price regressions show a similar pattern of slowest growth in strongest markets. Adjusted days increased 7 percentage points less in the

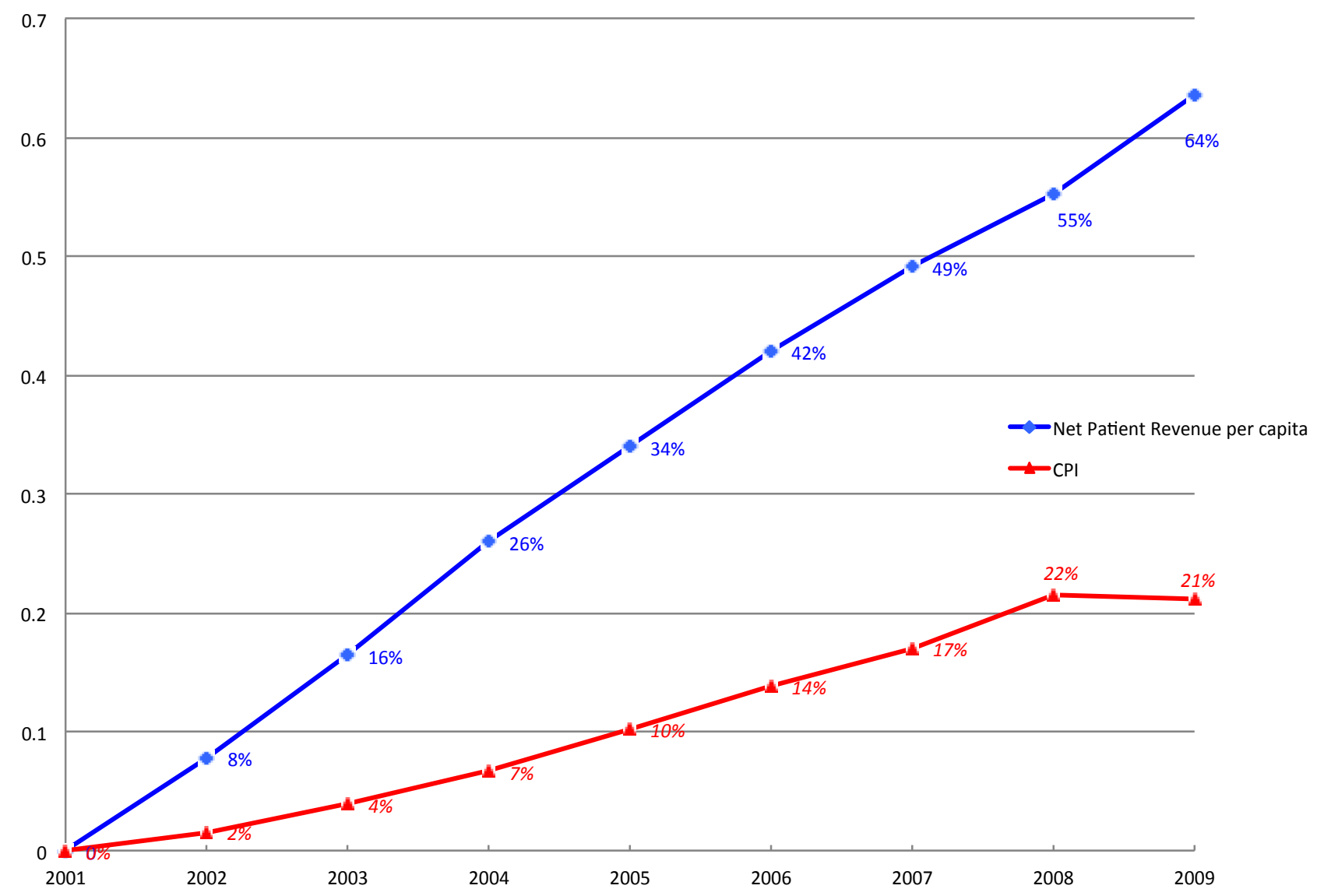

Figure 1. Cumulative growth in nominal hospital net revenue per capita compared to consumer price index (CPI), 2001 to 2009. 


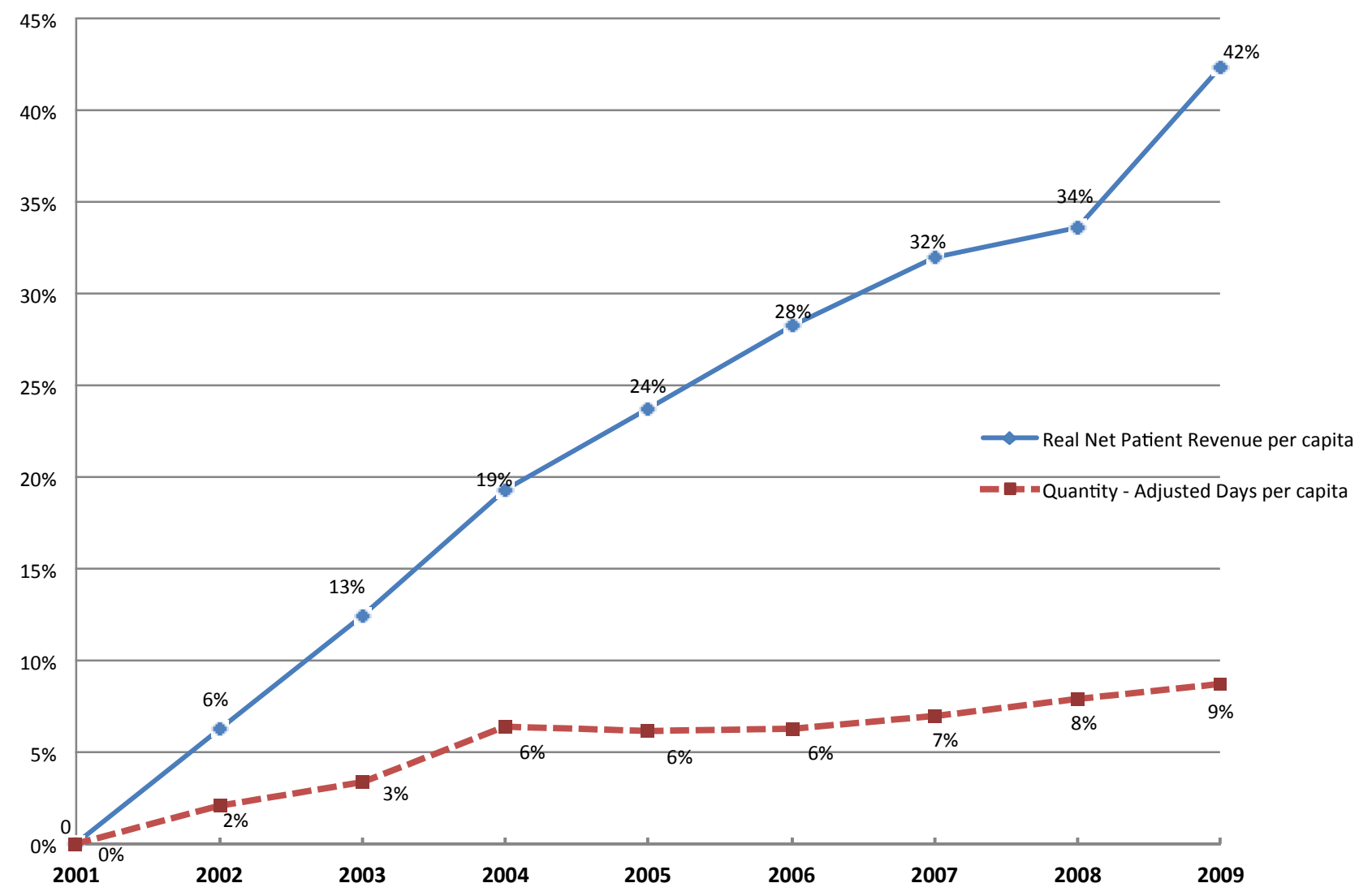

Figure 2. Cumulative growth in real hospital net revenue and quantity, 2001 to 2009.

Table 1. Regression adjusted growth by strength of market competition.

\begin{tabular}{lccccc}
\hline & Strongest Markets & Strong Markets & Average Markets & Weak Markets & Weakest Markets \\
\hline $\begin{array}{l}\text { Cumulative Growth } \\
\text { between 2001 and 2007 }\end{array}$ & $\begin{array}{c}\text { High MC Concentration } \\
\text { within Strong Markets }\end{array}$ & $\begin{array}{c}\text { Low MC Concentration } \\
\text { within Strong Markets }\end{array}$ & $\begin{array}{c}\text { All Other } \\
\text { Areas }\end{array}$ & $\begin{array}{c}\text { High MC Concentration } \\
\text { within Weak Markets }\end{array}$ & $\begin{array}{c}\text { Low MC Concentration } \\
\text { within Weak Markets }\end{array}$ \\
\hline Net Patient Revenue (Real) & $26 \%^{* *}$ & $33 \%^{* *}$ & $30 \%^{* *}$ & $35 \%^{* *}$ & $37 \%^{* *}$ \\
Adjusted Patient Days & $7 \%$ & $8 \%$ & $10 \%^{*}$ & $10 \%$ & $14 \%^{* *}$ \\
Net Patient Rev per Day & $16 \%{ }^{* * *}$ & $21 \%^{* *}$ & $18 \%^{* * *}$ & $21 \%{ }^{* * *}$ & $22 \%^{* *}$ \\
\hline
\end{tabular}

Note: 1) Strong markets are defined as MSAs high MC penetration, and high hospital competition (above 50 percentile in their distributions); 2) Weak markets are defined as MSAs high MC penetration, and high hospital competition (below 50 percentile in their distributions); 3) Regression models include dummies for each markets, change in percent total hospital spending by Medicare in a state, change in percent total hospital spending by Medicaid in a state, change in case-mix index, change in unemployment rate, and change in percent population that is $>65$; ${ }^{* *}$ Indicates significance level at 0.05 and ${ }^{*}$ at 0.1 in the regressions.

strongest markets than in the weakest markets, and the difference is 6 percentage points in net revenue per adjusted day, respectively. Comparison across rows within each column provides the relative contribution of price and quantity to total growth. Price increases drive total net patient revenue growth across all markets. Price grew 2.3 times faster than quantity in the strongest markets $(16 \% / 7 \%=2.3)$ and 2.6 times in the strong markets $(21 \% / 8 \%=2.6)$.

\section{DISCUSSION}

Research has shown that historically greater MC pene- tration coupled with more competitive hospital markets placed downward pressure in total hospital spending, operating mostly through lower prices. In this study we add a third potential source of market pressure, MC plan (HMO + PPO) concentration interacted with MC penetration and hospital competition.

The results paint a picture of market forces losing their punch, especially with respect to controlling price increases. Even in the strongest markets where the combined pressure from high MC penetration, hospital competition and health plan concentration is greatest, per capita hospital spending grew much faster than inflation 
and GDP growth (1.3 percentage points above real GDP growth of 2.7 in 2001-2007, authors' calculation). In those markets with less competitive pressure, spending grew even faster.

Decomposition of total spending provides some surprising results. We find, contrary to expectations, hospital utilization did not surge during the study period (3 - 8 percent based on alternative measures). Our finding adds to several recent reports, which found sharply rising hospital prices between 2008 and 2011 [9-15], indicating that rising hospital prices is not a recent or short-term phenomenon. Rather, hospital prices have been rising rapidly and driving hospital spending throughout the 2000's. While we cannot study them directly, we offer several possible explanations. Per capita demand for hospital services may be affected by new medical technology that reduces the need for some hospitalizations and length of stay. Also, MC plans, while relaxing direct utilization controls also increased cost sharing and case management programs while hospital bed capacity was relatively fixed, in part by nursing shortages.

Another key finding pertains to emerging trend of price increases in explaining per capita hospital spending. We found that much of the spending growth is due to higher revenue per unit of output, regardless of strength of market. Even in the strongest markets, price rose more than twice as fast as utilization. The trend that price is now driving total spending is in contrast to studies in the 1990's that found MC lowered overall expenditure primarily by price discount [23]. While our data do not allow us to test the underlying causes of this price driven trend, we offer some possibilities. The price bargaining position of health plans has weakened vis-à-vis hospitals [24-27]. Changes in treatment intensity and/ or technology can increase the spending per unit of hospital output. Also, improved quality may play a role resulting from new public and private quality improvement initiatives (e.g., report cards, pay-for-performance). Clearly, further research is needed to test these and other hypotheses. Given our data, we are unable to address the intensity, quality, and other issues directly.

\section{CONCLUSION}

With health reform bringing tens of millions of people into the health care system, rapidly rising health spending remains a pressing economic issue of our time. The reform law relies in part on market forces to control future spending for the newly insured population. Our results show that spending on hospital care grew by a substantial margin above CPI during the 2000's and that this trend is driven by a new and troubling factor-rapidly rising hospital prices. Even in markets where competitive forces are the strongest, hospital price increases made up nearly two thirds of the increase in total per capita spending. Our findings suggest that the US health care market has lost the competitive vigor needed to keep downward pressure on prices. Greater attention and efforts are needed in both the public and private sectors to restore price competition. Antitrust agencies should move more aggressively to protect and restore price competition. Private sector innovation is needed to increase consumer price shopping both in the insurance markets and for medical care services. If competitive balance is not restored soon, we face the prospect of higher health care prices, increased health insurance premiums and a growing call for greater government regulation.

\section{REFERENCES}

[1] Dor, A., Grossman, M. and Koroukian, S.M. (2004) Hospital transaction prices and managed-care discounting for selected medical technologies. American Economic Review, 94, 352-356. doi:10.1257/0002828041301786

[2] Mooney, C. and Zwanziger, J. (2005) Has competition lowered hospital prices? Inquiry, 42, 73-85. doi:10.5034/inquiryjrnl_42.1.73

[3] Zeckhauser, R., Altman, D. and Cutler, D. (2003) Enrollee mix, treatment intensity, and cost in competing indemnity and HMO plans. Journal of Health Economics, 22, 23-45. doi:10.1016/S0167-6296(02)00094-2

[4] Antwi, Y., Gaynor, M. and Vogt, W. (2009) A bargain at twice the price? California hospital prices in the new millennium. Forum for Health Economics and Policy, 12, 3.

[5] Bundorf, M.K., Royalty, A. and Baker, L.C. (2010) Health care cost growth among the privately insured. Health Affaris, 28, 223-221.

[6] Kemper, N., Ginsburg, P.B. and Berenson, R.A. (2010) Unchecked provider clout in California foreshadows challenges to health reform. Health Affaris, 29, 699-697. doi:10.1377/hlthaff.2009.0715

[7] Vladeck, B.C. and Rice, T. (2009) Market failure and the failure of discourse: Facing up to the power of sellers. Health Affaris, 28, 1305-1311. doi:10.1377/hlthaff.28.5.1305

[8] Friedman, B.S., Wong, H.S. and Steiner, C.A. (2006) Renewed growth in hospital inpatient cost since 1998: Variation across metropolitan areas and leading clinical conditions. American Journal of Managed Care, 12, 157166.

[9] Gaynor, M.S. and Newman, D. (2010) Health care cost and utilization report: 2010. The Health Care Cost Institute, Washington DC.

[10] The Health Care Cost Institute (2012) Changes in health care spending in 2011. The Health Care Cost Institute, Washington DC.

[11] Shapiro, A. (2013) What's driving medical care spending growth? FRBSF economic letter. Federal Reserve Bank of San Francisco, San Francisco.

[12] National Institute for Health Care Management (2001) 
Understanding US health care spending. Data brief. National Institute for Health Care Management, Washington DC.

[13] Maryland Health Care Commission (2012) State health care expenditures. Spotlight on Maryland. Maryland Health Care Commission, Baltimore.

[14] Peterson, H. (2012) Hospital rates jump across Washington region. Washington Examiner, Washington DC.

[15] Lemieux, J. and Mulligan, T. (2013) Trends in inpatient hospital prices, 2008-2010. American Journal of Managed Care, 19, e106-e113.

[16] Pauly, M.V. (1998) Managed care, market power, and monopsony. Health Services Research, 33, 1439-1422.

[17] Sorensen, A.T. (2003) Insurer-hospital bargaining: Negotiated discounts in post-deregulation connecticut. Journal of Industrial Economics, 51, 469-422. doi:10.1111/j.0022-1821.2003.00211.x

[18] Wu, V.Y. (2009) Managed care's price bargaining with hospitals. Journal of Health Economics, 28, 350-311. doi:10.1016/j.jhealeco.2008.11.001

[19] Baker, L.C. (2001) Measuring competition in health care markets. Health Services Research, 36, 223-251.

[20] Chernew, M., Scanlon, D.P., Lee, W. and Swaminathan, S. (2006) Competition in health insurance markets: Limitations of current measures for policy analysis. Medical Care Research and Review, 63, 37S-55S.

[21] Madison, K. (2004) Multi-hospital system membership and patient treatments, expenditures, and outcomes. Health Services Research, 39, 749-769. doi:10.1111/j.1475-6773.2004.00256.x

[22] Chakravarty, S.G.M., Klepper, S. and Vogt, W. (2006) Does the profit motive make Jack nimble? Ownership form and the evolution of the US hospital industry. Health Economics, 15, 345-361. doi:10.1002/hec.1111

[23] Baker, L., Atlas, S. and Afendulis, C.C. (2008) Expanded use of imaging technology and the challenge of measureing value. Health Affaris, 27, 1467-1478. doi:10.1377/hlthaff.27.6.1467

[24] Gertler, P.J. and Cuellar, A.E. (2005) How the expansion of hospital systems has affected consumers. Health Affairs, 24, 213-219. doi:10.1377/hlthaff.24.1.213

[25] Melnick, G. and Keeler, E. (2007) The effects of multihospital systems on hospital prices. Journal of Health Economics, 26, 400-413. doi:10.1016/j.jhealeco.2006.10.002

[26] Berenson, R., Ginsburg, P., Christianson, J. and Yee, T. (2011) The growing power of some providers to win steep payment increases from insurers suggests policy remedies may be needed. Health Affairs, 31, 973-981. doi:10.1377/hlthaff.2011.0920

[27] Berenson, R.A., Ginsburg, P.B. and Kemper, N. (2010) Unchecked provider clout in California foreshadows challenges to health reform. Health Affairs, 29, 699-705. doi:10.1377/hlthaff.2009.0715 